Cuadernos de Filología Clásica. Estudios Latinos ISSN: 1131-9062

http://dx.doi.org/10.5209/CFCL.57803

\title{
La tradición indirecta de las Geórgicas de Virgilio y su recepción ecdótica ${ }^{1}$
}

\author{
Ángel Escobar ${ }^{2}$
}

Recibido: 30 de enero de 2017 / Aceptado: 10 de septiembre de 2017

Resumen. La tradición indirecta de las Geórgicas plantea todavía a los editores del texto numerosas dudas, cuya solución - al menos en sus aspectos prácticos - sigue requiriendo en nuestra opinión un análisis de los pasajes en su conjunto, tendente a la observación de paralelismos y a la aplicación de un proceder ecdótico más coherente. Tras un breve resumen de la transmisión antigua y medieval de la obra virgiliana en cuestión, con atención particular a los problemas que afectan a su rica tradición indirecta, nuestro trabajo resalta la relativa disparidad de criterios que viene ofreciendo la práctica editorial, incluida la más reciente, y plantea la conveniencia de uniformizar algo más — siempre en la medida de lo posible - la aplicación de tales criterios, tanto en lo que concierne a cuestiones de contenido y de cierta envergadura literaria (así, por ejemplo, la referente al empleo de arcaísmos) como a las meramente ortográficas.

Palabras clave: Virgilio; Georgica; Tradición indirecta.

\section{[en] The indirect tradition of Virgil's Georgica and its editorial reception}

\begin{abstract}
The indirect tradition of Virgil's Georgica still poses many problems to the editors of this text, whose solution, at least in practical terms, requires an analysis of the passages as a whole, which should lead to a more systematic study of parallelisms and to a more coherent ecdotic praxis. After presenting a summary of the ancient and medieval transmission of this Virgilian poem, with particular attention to the problems of its very rich indirect tradition, our paper tries to show the disparity of ecdotic criteria even in very recent times. We question whether the application of these criteria could be more rigid, only as far as possible, both with regard to literary questions (like the very controversial use of archaisms by Virgil) and to merely orthographic conventions or preferences.
\end{abstract}

Keywords: Virgil; Georgica; Indirect tradition.

Sumario. 1. Introducción: vías de transmisión de las Geórgicas. 2. La recitación en Atela. 3. La 'segunda edición' de Georg. IV. 4. Otras posibles intervenciones tempranas. 5. Diversidad de criterios editoriales. 6. Conclusiones. 7. Referencias bibliográficas.

Cómo citar: Escobar, Á., «La tradición indirecta de las Geórgicas de Virgilio y su recepción ecdótica», Cuad. Filol. Clás. Estud. Lat. 37.2 (2017), 219-238.

\footnotetext{
El autor agradece a los evaluadores del artículo sus valiosas sugerencias.

2 Universidad de Zaragoza.

aescobar@unizar.es
} 


\section{Introducción: vías de transmisión de las Geórgicas}

La primera difusión por escrito de los cuatro libros de las Geórgicas ${ }^{3}$ (quizá en un rollo de papiro por libro ${ }^{4}$, aunque no necesariamente) debió de producirse de manera rápida y diversificada ya entre el año 29 (recitación en Atela) y el 26 a. C., muerte de Cornelio Galo y comienzo de una elaboración intensa de la Eneida: Jacobson (1984, 320), Martin $(1985,666)$. Sólo cabe especular sobre la posibilidad de que se depositase un ejemplar 'oficial' de la obra en la Biblioteca Palatina que dirigió Higino (SVEt.Gramm. et rhet.20), ya sea en el año 29, en el 26 - si es que el libro IV fue revisado por su autor, al menos en lo concerniente a Galo - o en ambas ocasiones. Tampoco resulta posible identificar uno de estos dos hipotéticos ejemplares, sucesivamente autorizados en principio por el poeta, con el libro (liber) ex domo atque familia Vergilii que Higino afirmaba en sus comentarios haber manejado a propósito del tema de su interés tratado en Georg.2.246-247 (Gel.1.21; cf. Colum.9.2.1, Goodfellow $(2015,55)$ y, sobre el posible aspecto del ejemplar en cuestión, Dorandi $(1991,23))$.

Es verosímil que la obra llegara a transmitirse de manera exenta y que aún puedan intuirse «traces of an independent phase» (Geymonat 2001, 294-295). Sin embargo, nada impide que lo hiciera asimismo junto con Bucólicas, durante un primer periodo, y ya también con Eneida a partir de la muerte del poeta (19 a.C.) y de la edición realizada por Vario $c$. 17-16 a. C. (poco antes de morir éste y a partir de materiales que quizá dejaban oscuras algunas decisiones de Virgilio: Tarrant 2012, 465). De ser así, lo haría probablemente en un corpus de transmisión conjunta (como el predominante en el siglo II: Gamberale 1977, 366) y ordenado de modo cronológico (Buc., Georg. y Aen.; $c f$. por ejemplo Ov.Am.1.15.25-26), provisto de una elemental puntuación, según el procedimiento diacrítico usual en la época ${ }^{6}$, cada vez más uniformizado en lo ortográfico y, seguramente desde muy temprano, ya en formato de códice, tanto en papiro como - con paulatina frecuencia - en pergamino (ya que la publicidad que ofrece Marcial en sus Apophoreta - sobre todo en XIV 186 - no tiene por qué referirse a un producto librario novedoso por su material o su formato). Es el tipo de transmisión que cabía esperar de la condición de ‘clásico' que ostentaba su autor, desde que Quinto Cecilio Epirota - fundador de escuela en Roma en torno al 26 a. C., tras la desaparición de su amigo Galo - lo incluyese como joven promesa en su selección de autores 'modernos' (Suetonio, Gramm. et rhet. 16, 3, ed. Kaster: primusque [sc. Caecilius

Sobre posibles diseños virgilianos previos — sólo con los dos primeros libros por ejemplo, como sugiere el colofón o cierre de Georg.2.541-542 (ed. Conte: Sed nos immensum spatiis confecimus aequor, / et iam tempus equum fumantia soluere colla) y, quizá, Prop.2.34.77-78 (ed. Fedeli: Tu canis Ascraei veteris praecepta poetae, / quo seges in campo, quo uiret uиa iugo)_, cf. Martin (1985, 666-668) y Goodfellow $(2015,60)$.

$4 \quad C f$. Zetzel $(1984,143)$, a propósito de las variantes en Georg. IV atribuidas a Hebro/Ebrius y Corneliano, Erren $(2003,8)$ o, con infundada rotundidad, Kallendorf $(2015,42$ : «a roll could hold only one book»).

5 No consta que Vario revisase también Bucólicas o Geórgicas, pese a que en la Vita Donati $(V D$, lín. 158) se aluda al conjunto de los escritos (Stok 2010, 111-112, 117; cf. Cova (1990, 442), Jocelyn (1985, 470, n. 190), ambos con referencia al Servio Danielino a propósito de Buc.7.65: in Vari et in Hebri, donde podría aludirse tan sólo al Vario citado por Hebro).

$6 \quad C f$. Quint.11.3.36-38, en referencia al inicio de Eneida (Geymonat 1985c); son muy escasos los testimonios que permiten especular sobre el aspecto de una edición de época virgiliana, reducidos casi al 'papiro de Galo' (paralelo latino, por así decirlo, del 'nuevo' Posidipo de Pela), fragmento de un volumen en capital de época de Augusto (45-44 a. C., según Gagliardi 2009, 63) y producido probablemente en la misma Roma (Cavallo 2008, 156), quizá a instancias de un gramático (Somerville 2007). 
dicitur] Vergilium et alios poetas nouos praelegere coepisse; quod etiam Domiti Marsi uersiculus indicat: Epirota, tenellorum nutricula uatum).

La transmisión directa conservada responde a esa amplia difusión de las Geórgicas, si bien los testimonios epigráficos (graffiti por ejemplo: Cugusi 2008, 488) y papiráceos que la atestiguan son escasos ${ }^{7}$ y de muy limitada relevancia textual (como lo ha sintetizado Zetzel $(2016,562)$, a propósito de los segundos: [...] «nowhere does any of these texts provide a correct reading not otherwise attested, or even otherwise scantily attested; they confirm no convincing conjecture from later times»). Resulta inviable documentar la existencia de ediciones antiguas como la supuestamente confeccionada por Julio Montano bajo Tiberio, la cual, según ha llegado a sostenerse, habría obstaculizado la circulación de otras ediciones contemporáneas (Zwierlein 1999, con crítica de Zetzel 2000, Galinsky 2002). Suscita grandes dudas el tipo de labor que debe atribuirse a Probo (Jocelyn 1985, 469; Geymonat 1986, 118; Delvigo 1987; Lehnus 1988; Kaster 1995, 248, 258, 263) y muy poco ha sobrevivido, asimismo, del trabajo crítico de Cornuto, Aspro o Celso (Arruncio, según Timpanaro (2001, 25-26), o Cornelio).

Los principales códices virgilianos conservados datan de época tardoantigua y se hallan escritos en capital. Son tres y constituyen el principal recurso para la fijación del texto en su conjunto (el «editor's mainstay»: Reynolds, 1986, 433), pese a las extensas lagunas que dos de ellos ofrecen en el caso de Geórgicas: M (Mediceus $=$ Laur. $\left.39,1^{8}\right)$, P $\left(\right.$ Palatinus $=$ Vat. Pal. Lat. $1631^{9}$; no transmite Georg.1.323-2.138 y 4.462-566) y R (Romanus = Vat. Lat. 3867 ${ }^{10}$; no transmite Georg.2.1-214 y 4.37-180). Según Conte $(2013,101)$, cabe conceder cierta preferencia al códice M: fere ergo ad MPR necesse est confugere, quorum consensus magni est aestimandus. Plurimum pollent ad textum constituendum Mediceus et Palatinus, at neuter eorum contra alterum praecellere aperte uidetur, quamquam Mediceum puto aliquanto frequentius lectiones seruauisse ueras (con ejemplos relativos a $\mathrm{M}$ y $\mathrm{P}$-ya destacados por Geymonat (1985a, 293) — en n. 19); el «probiano» P sería modélico en cuanto a ortografía según Sabbadini (Geymonat 2008, XVII, n. 53); a la peor calidad del texto de R, en general, se refirió, tras Geymonat, Timpanaro (2001, 10, n. 20), si bien Conte ha señalado ( $i b$.) IV 509, flesse sibi et, como lectura correcta sólo conservada en R y ha alabado el mérito de este mismo testigo en 1.360, a curuis, 2.382, ingeniis, y 3.433,

Cf. Reynolds (1986, 435, n. 14), con referencia a los cuatro papiros principales; Gigante (1986b, 28-30), con especial atención al P. Ant. I 29 ( $\left.\Pi^{3}\right)$; resto (cinco fragmentos de un mismo folio, con el final de Georg.2 y el inicio de 3) de una edición en códice de papiro — de gran formato: 40 x 27,5 cms., como manufactura egipcia o siria de lujo- del s. IV-V, así como Petrucci (1987, 964-965), Scappaticcio (2009a, 112-113, n. 4; 2009b, 239, n. $3 ; 2013)$.

8 Único códice tardoantiguo que transmite Georg. 2.1-91 y 118-138, escrito en Roma c. 494-495 (Geymonat 2008, XIX), a partir supuestamente de un modelo en minúscula (cf., tras Timpanaro, Cadili 2008, 203, n. 38; «Kapitaliskursive» según Brunhölzl (1971, 24); cf. Geymonat (1985a, 294; 1986, 121) y, con referencia a Georg.1, Gaebel 1985). Su texto, corregido en Roma según subscripción, quizá autógrafa, por Asterio (cónsul en 494; $c f$. Ammannati 2007), ya se encontraba prefigurado a finales del siglo IV, a juzgar por las citas de Ausonio (Bonaria 1971, 39). Contiene una cuarentena de glosas a Buc., en ff. 2r-8r (Munk 2009, 111).

9 Ejemplar de lujo escrito en Italia a finales del siglo V o principios del VI (Ammannati 2009, 253; Geymonat 2010,354); sobre su posible antígrafo en minúscula, $c f$. Brunhölzl 1971, 23 (a un modelo próximo a la cursiva se había referido Marichal 1957, 84); su texto se hallaría prefigurado a mitad del siglo IV según Bonaria (1971, 39), a juzgar por las citas del centón de Proba ( $c f$., no obstante, Moretti 2008 y, en general, Salanitro 2013).

10 Copiado a mediados del siglo VI en el mismo escriptorio de Roma o de Ravena en que se copió P (Geymonat 2008, XX); sobre las glosas de tipo didáctico que debía de presentar su antígrafo, $c f$. Geymonat $(1986,112)$. 
exsilit. Otros cuatro códices tardoantiguos conservan nuestra obra de modo muy fragmentario: F (=Fulvii Ursini schedae Vaticanae = Vat. Lat. $\left.3225^{11}\right)$, V (Veron. XL $\left.[38]^{12}\right)$, A (Augusteus = Vat. Lat. 3256 y Berol. Lat. Fol. $\left.416^{13}\right)$ y G $\left(\right.$ Sangall. 1394 $\left.{ }^{14}\right)$.

Resulta difícil probar la existencia de un arquetipo como el propuesto en su día por Ribbeck, pese a su innegable utilidad como modelo explicativo (unum archetypum [...] oppletum uariis lectionibus et glossematis, ap. Geymonat 1985a, 292, 1986, 119), el imaginado por Perret, quien lo fechaba en el siglo III y al que atribuía una finalidad escolar $(1973,380)$ o como el defendido con gran convicción por Courtney (siglo $\mathrm{IV}^{15}$ ), si bien no deja de constituir un imperativo metodológico - $\tan$ remoto y abstracto como se desee - incluso en una transmisión como la virgiliana (Escobar 2008). Más inverosímil parece que los siete códices tardoantiguos conservados puedan ofrecer - tanto en el caso de Geórgicas como en el del resto del corpus- "una tradición textual independiente para cada uno de ellos" (Rivero et al. 2009, CLXXV $\mathrm{y}$, en sentido similar, CLXXX), por mucho que esta representación refleje en cierta medida la recta uia sugerida por Pasquali (Geymonat 1977, 116; 1985a, 291; 1986, 116), bajo la que subyacía, en realidad, la hipótesis de un arquetipo muy antiguo, próximo en cronología y fisonomía al propio original.

En ausencia del comentario de Elio Donato a todo Virgilio (med. s. IV), recopilación en la que ya sólo se recogían de multis pauca, según la carta introductoria a Munacio, hay que reseñar, por una parte, los escolios 'no servianos': los Scholia Veronensia y los Scholia Bernensia (entre cuyas fuentes de los siglos IV y V suele destacarse el nombre de Iunilius Flagrius, 'Filargirio' o 'Filagrio', tradicionalmente asociado con la Brevis expositio que comprende Georg. I y parte de II; en opinión de Munk (2009, 12), estos Scholia Bernensia remontarían a un texto de Virgilio con glosas del siglo $\mathrm{V}^{16}$ ). Debe mencionarse, por otra parte, la recopilación de Servio (principios del s. V), realizada por su autor con posterioridad a la sección referente a Eneida (Brugnoli 1988, 807), con Donato como fuente esencial pese a verse éste criticado a veces con dureza. La abigarrada y compleja 'segunda redac-

11 Transmite Georg.3.1-21, 146-214, 285-348; 4.97-124, 153-174, 471-497 y 522-548. Escrito en Roma hacia finales del siglo IV (c. 375-425, según Horsfall 2000, XXX), es posible su relación con el entorno de Símaco (Geymonat 2008, XX).

12 Copiado a finales del siglo V (c. 475-490), transmite Georg.2.92-117, 274-299, 352-377, 535 - 3.12, 351$402,4.436-464$ y 522-549; posible origen en Galia (Lowe), donde se encontraba hacia el año 700 y se reutilizó como palimpsesto a principios del s. VIII, o en Italia (Seider; $c f$. Geymonat 2010, 354, quien sugería en 2008, XXI un origen próximo a Mantua). Conte (2013, 101, n. 18) destaca sus lecturas en 2.296 (pandens) y 4.461 (impleuit).

13 De principios del s. VI y posible origen italiano (Horsfall 2000, XXX; Geymonat 2001, 294-295, n. 5, y 306307 ; 2010, 354), transmite Georg.1.41-280 y 3.181-220; un supuesto antígrafo en capital, copia a su vez de otro en cursiva de los siglos II-III, ha propuesto Velaza $(2001,42)$. Conte $(2013,101$, n. 18) destaca su testimonio único en I 135 (pro ut legit et, quod non spernendum uidetur; et edita Jeunet-Mancy en Serv. ad Aen. VI 7).

14 De finales del siglo V (Horsfall 2000, XXX) o principios del VI y posible origen italiano (Geymonat 2010, 354), transmite Georg.4.345-362, 364-381, 383-400, 402-419 y 535-566; Conte 2013 (101, n. 18) destaca su testimonio exclusivo en 4.415 (defundit).

15 Courtney 1981 y 2002-2003; pero $c f$., tras Timpanaro, Geymonat (2008, XV, n. 41), Moretti (2008, 80, n. 118) y Escobar 2008.

16 Cf., no obstante, Kiss (2012, 118); en general cf. Geymonat 1985b, 520; Cadili 2003; Conte 2013, 106; Goodfellow 2015, 57, n. 38; la presencia de glosas en antiguo irlandés, en sus dos redacciones, y algunos rasgos gráficos han hecho pensar en un origen insular (Daintree - Geymonat 1988, 709, 716), quizá del entorno de Adamnano, abad del monasterio escocés de Iona ( $o b .704)$, a quien también ha querido vincularse con el Servio Danielino (DS; cf. Jeunet-Mancy 2012, 26). 
ción' de los escolios servianos, ya presente en manuscritos del siglo IX y editada en 1600 por Pierre Daniel, se conoce como Seruius auctus o Danielis / Danielinus Seruius $(D S)$; de origen quizá insular y datable en el siglo VII, su texto de base parece hallarse más próximo que el de Servio a la vulgata manuscrita de la época (Stok 2012); Funaioli y otros han creído identificar bajo el $D S$ el comentario de Donato (al que no alude en ningún momento: Brugnoli 1988, 809-810, Munk 2009, 11 y 37 , Stok 2012,129), mientras que algunos estudiosos creen que contiene también material exegético predonatiano (cf. Holtz 2011, 212, 217); ciertas similitudes con los Scholia Veronensia han hecho pensar en una fuente común, quizá de origen galo (Baschera 2008, 213).

No se conservan manuscritos datables en los siglos VII y VIII, ni siquiera fragmentarios, pero los del siglo IX y siguientes son numerosos. Suelen verse afectados por procesos de contaminación intensos, si bien han podido determinarse algunas relaciones entre estos códices y sus precedentes tardoantiguos, observándose por ejemplo que el Guelf. 70 Gud. Lat. (= $\gamma$; escrito quizá en Lyon en el siglo IX ${ }^{17}$ ) sigue el texto de $\mathrm{P}$ en el caso de Eneida, dependencia menos explícita en el caso de Geórgicas (Ammannati 2009, 254, n. 5; Ammannati - Pittà 2013, Conte 2013, 105 y 2016a, 26: «an apographon of $\mathrm{P}$ for the text of the Aeneid [...] descends from a codex corrected on the basis of $\mathrm{P}$, does not depend on $\mathrm{P}$ for the text of the Georgics»). Mynors adujo en su edición el testimonio de una decena de códices del siglo IX ${ }^{18}$; Geymonat añadió el de otros cuatro manuscritos de los siglos IX-XI ${ }^{19}$ y también Conte hizo un esfuerzo de colación en el mismo ámbito (2013, 102: lectiones quoque multas addidi ex Carolinis libris in hanc editionem de professo collatis, ut nostrae explorationis noui fructus memoriae mandarentur, 103-105). Creemos que la posibilidad de que los manuscritos carolingios representen a veces una recensión periférica (una «provincial paradosis», según Kraggerud 2016) debe todavía sustentarse adecuadamente. En cualquier caso, el aporte de estos manuscritos está por demostrar, de modo que sigue siendo fundada la cautela al respecto de Mynors (1972, XI: in isto pelago alius trahat umida lina): pese al gran mérito de colaciones recientes (Librán, Ramires, etc.), la búsqueda entre los recentiores no ha dado por el momento, como también ocurre en transmisiones más o menos afines (la ovidiana, por ejemplo), grandes frutos para la constitutio.

Desde la princeps romana de c. 1469, las Geórgicas han conocido numerosas impresiones. En época moderna las ediciones completas de mayor trascendencia, tras las pioneras de Ribbeck y Sabbadini, han sido las de Mynors (1969, ed. correg. 1972), reimprimida con comentario en 1990, Geymonat (1973; $2^{\mathrm{a}}$ ed., con addenda et corrigenda, publicada en Roma, 2008), Erren (1985, con extenso comentario publicado en 2003), Thomas $\left(1988\right.$, con notas ${ }^{20}$ y Conte (2013, quien para lo refe-

17 El texto de Georg.2.53-234, ausente en el Guelf. (Conte 2013, 122 y 146 ad loc.), se conserva en el Gotinga, Bibl. Univ., App. Dipl. 10 E Mapp. I, 28.

18 Entre los que cabe destacar s (Par. Lat. 7928, siglo IX ex.) con Georg. hasta 3.124 (Reynolds 1986, 435-436).

19 Como el Montepessulanus Fac. Med. 253, del segundo tercio del siglo IX; a propósito de $d h t$, cf. Geymonat (2008, XV, n. 41), quien en V, n. 3, aludía asimismo al manuscrito $n$ (s. X, in Italia inferiore ab exemplo descriptus est picturis ornato et nunc deperdito); Erren colacionó además el Hamburgensis Scrin. 52 (hasta Georg.4.52). Respecto a los Longobardici libri analizados por Ottaviano (familia $\Lambda$ ), cf. Conte $(2013,107)$. Para los accessus medievales y similares, $c f$. Munk $(2009,119-120)$.

20 Aunque, según Perutelli $(2005,110)$, «Mynors eccelle nell'interpretazione dei passi importanti e del poema nel suo complesso», los trabajos de Thomas y Mynors son perfectamente complementarios, máxime en casos 
rente a criterios editoriales remite en p. 102 a su edición de Eneida de 2009, XIXXXI). La edición de Mynors se convirtió durante décadas en el texto de referencia; presenta un aparato crítico muy escueto, a diferencia de Geymonat, que lo ofrece sobreabundante ${ }^{21}$ y resulta a veces insustituible (por ejemplo para inscriptio y explicit, elementos desatendidos por otros editores). El estudioso debe basarse hoy en los aparatos de Geymonat y Conte, sobre todo para lo referente a distinción de manos - pese a sus esporádicas discrepancias - y para discernir lo que ofrecen los manuscritos en los casos más confusos. Thomas prescindió de incluir un aparato crítico (ni siquiera de tan mínima y extravagante expresión como el propuesto recientemente por Myers (2009) para el libro XIV de las Metamorfosis ovidianas), pero ofreció un útil elenco de sus divergencias respecto a Mynors y Geymonat (primera edición), según el cual discrepaba de ambos en 16 lugares, coincidía con el primero en 11 y en otros 11 con el segundo; el mismo autor resaltaba el hecho de que, por su parte, «no new conjecture has been admitted to the text» (Thomas 1988, I 32-34, nn. 88-89), criterio distinto del seguido por Conte, quien ha adoptado cinco conjeturas, incluida una propia a 3.159: si quos (2016b, 95-98; desestimada por Heyworth (2014) y Holzberg (2016)). Según ha apuntado Butterfield $(2011,399)$, «the most significant means by which modern texts of Virgil differ is in their receptivity to conjectures» (o 'enmiendas', según prefiere Kraggerud 2016, necesarias en su opinión ya que «[...] the ancient paradosis is too lacunose and arbitrary to serve as the sole basis for the text»). Ciertamente, no debe descartarse de antemano la posibilidad de aceptar conjeturas o al menos de aducirlas, siempre que resulten necesarias para la fijación de un texto comprensible o para evitar una lectio excesivamente difficilior (es decir, impossibilis ${ }^{22}$ ).

El texto de Geórgicas, por tanto, se halla constituido con bastante fijeza, si bien sigue suscitando dudas, como recientemente ha intentado reflejar, por ejemplo, Giardina, al estimar que numerosos lugares - considerados tradicionalmente como sanos y no implicados, además, en problemas de tradición indirecta - todavía requieren

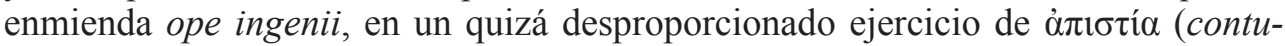
max suspicio, según Conte 2013, 95 y 98) y que — bajo el efecto de cierta prurigo emendandi - procede en ocasiones a normalizar el texto, a justificar variantes o conjeturas por el mero hecho de que darían sentido igualmente y quizá, en suma, a

en que uno u otro decae; así Mynors a 1.181, inludant (aprobado por Heyworth 2014 y Holzberg 2016, frente a la decisión de Conte: $c f .2016 b, 21-22)$ / inludunt, Thomas a 2.54, faciat / faciet, o ambos (2.106: discere / dicere).

21 Courtney (1981, 13: «abundant useless information»), Reynolds (1986, 433, n. 2: «it has a larger apparatus than is necessary or even convenient for normal purposes, but where extra information may be found»), Zetzel (2016, 562: «clogged apparatus»).

22 Cf. Courtney 1981, 27: «It follows that in spatio [Georg.1.513] has overwhelming authority; the only question that remains is, what does it mean? I have no idea what it means, though I think we are bound to accept it» (así Velaza 1998); in spatia ha admitido Conte, con Quint.8.3.78 (cód. A) y Servio (cf. Timpanaro 2001, 10, n. 21, Stok 2012, 108). Virgilio puede llegar a ser muy sugerente (cf. Jacobson 1982, a Georg.3.280-1: destillat = manat), incluso esotérico (Katz 2008), pero no incomprensible o absurdo. Por lo demás, «si può, tutto considerato, scartare una variante senza per questo 'aggredirla'» (Timpanaro 1986, 173, n. 16); es prudencia que solía aplicar Mynors al justificar sus preferencias, como en 1.35 (reliquit 'más expresivo' que relinquit; contra Kraggerud 2011, 224-225, n. 31, 2016, en apoyo de P y la tradición indirecta) o en 1.36 (sperant frente al también indirecto sperent, quizá motivado por ueniat), si bien se mostraba expeditivo en ocasiones (1.321: «all needless», 1.383: «this need raise no suspicions»). 
'corregir al autor' (Tarrant 1992, 31-32 y n. 91; Conte 2013, 9823). Como bien apuntó Horsfall (2000, XXXI), el texto virgiliano no debería verse «neither as a playground for natural conservatives nor as a pretext for brilliant emendations to eliminate a great poet's many singularities».

\section{La recitación en Atela}

Suele admitirse que las Geórgicas fueron elaboradas durante siete años (Vita Donati =VD, ed. Hardie, líns. 91-92: Bucolica triennio, Georgica VII, Aeneida XI perfecit annis ${ }^{24}$ ) y que fueron recitadas por su autor ante un convaleciente Octaviano en la localidad de Atela, en el verano del 29 a. C.: Georgica reuerso post Actiacam uictoriam Augusto atque Atellae reficiendarum faucium causa commoranti per continuum quadriduum legit, suscipiente Maecenate legendi uicem, quotiens interpellaretur ipse uocis offensione (ib., líns. 93-97). El hecho de que la recitación se prolongase durante cuatro días debe entenderse seguramente como alusión al número de libros de que ya constaba la obra en ese momento ${ }^{25}$.

23 Cf. Giardina 2009, con 26 propuestas en este sentido, ninguna de ellas mencionada por Conte 2013. En 1.50 (ferro] rostro - scindimus] findimus) propone entender aequor metafóricamente, como el 'mar' de la poesía, sustituyendo el texto transmitido de forma unánime y eliminando la frecuente asimilación — no menos metafórica- entre 'arar' y 'navegar' (Thomas 1988, I 76-77, Mynors 1990, 12); en 1.76 (comantem, ya que «il participio sonantem non si giustifica») no se aportan paralelos virgilianos y se omite la referencia a pasajes afines, como el celebérrimo resonare siluas de Buc.1.5; en 1.115 (incertis] intortis - mensibus] flexibus) no se aportan paralelos de intorti flexus ni se alude a la dificultad de incertis mensibus, «meses inestables» (primavera y otoño según se desprende de Thomas 1988, I 86; Mynors 1990, 25; Erren 2003, 78, si bien parece dudoso que sea «verschoben von incertus amnis»); en 1.205 se propone lubricus, pero lucidus es lo que cita Colum.11.1.31, y poco parece obligar que Virgilio aplique lubricus en Aen.5.84 (al animal, no a la constelación; cf. Mynors 1990, 47: «Draco is put here [...] because it is a noble object, a glittering river of light in the northern sky»); en 1.362 (clamorem] clangorem [Heyne praeeunte; $c$. p. ej. Aen.3.226] - litora] sidera) se justifica ad sidera mediante tres pasajes con clamor (como Aen.2.222, en conexión con tollere) y se pierde un ex aequore ... ad litora que es literal en el modelo virgiliano (Arato, Phaen. 913 y 914 respectivamente); en 1.429 (pelagoque] pecorique) sólo se fundamenta la conjetura en el hecho de que ofrece supuestamente «una frase molto più idiomatica», aun a costa de suprimir una oposición común (terra marique; el paralelo de Georg.4.443-444 aducido carece del elemento humano y apenas cabe esgrimirlo). Similares objeciones cabe hacer, en nuestra opinión, a buena parte de las propuestas para los demás libros: 2.11 (flumina] litora, para forzar la unión con su perpetuum epitheton —según Servio-curua), 2.199-200 (flumine] gramine, gramina] flumina), 2.263 (curant] durant), 2.272 (consuescere] coalescere), 2.285 (animum ... inanem] animo... inani, pascat] pateat), 2.297 (sustinet] sufficit), 2.320 (longis] nigris, sustitución también sugerida para 3.200), 2.407 (fingitque] frangitque), 2.441 (feruntque] premuntque), 2.463-464 (postis] lectos, inlusasque... uestis] incusosque... postis), 2.468 (latis] laetis, también sin paralelos para la juntura; por lo demás, laetis es lectura de tradición directa: Conte 2013, ad loc. [ms. g], aprobada por Heyworth 2014), 2.469 (uiuique] niueique), 2.477 (accipiant] praecipiant, uias] fort. uices), 2.503 (caeca] saeua; un caso claro, en nuestra opinión, de empobrecimiento literario del sentido), 3.143 (uacuis] patulis), 3.285 (circumuectamur] circumspectamus), 3.354 (alto] acri), 4.7 (numina] omina), 4.52 (reclusit] refulsit), 4.126 (niger] piger). Las propuestas de Giardina merecen el máximo respeto, porque reflejan un extraordinario conocimiento del lenguaje virgiliano, pero, en nuestra opinión, ofrecen en realidad loci similes, de valor propedéutico, no enmiendas.

24 Si bien el último Mynors se mostraba escéptico al respecto (Nisbet ap. Mynors 1990, V); sobre la posible influencia de la tradición numerológica en este tipo de testimonios, $c f$. Martin $(1985,664)$.

25 F. della Corte $(1991,68)$, quien también aludía a los aspectos menos literarios del episodio (71-73); podría tratarse de la lectura evocada por Horacio en Carm.3.4.37-40: Vos Caesarem altum, militia simul / fessas cohortes abdidit oppidis, / finire quaerentem labores / Pierio recreatis antro. Nisbet - Rudd (2004, 54-55 y 69) insinúan la posibilidad de que Horacio se hallase entre los oyentes. 
De aceptarse la veracidad de este episodio, que no parece que la tradición biográfica haya forjado de manera gratuita a partir de las interpelaciones que se observan en Georg.1.40-42 y 2.39-46 (a Augusto y a Mecenas respectivamente) ${ }^{26}$, hay que admitir que esta primera divulgación de las Geórgicas, similar a la que experimentaron c. 22 a. C. los libros 2, 4 y 6 de la Eneida (VD, lín. 112), fue de carácter oral, aunque lo natural es que tal difusión se produjese ya también por escrito, tanto entre los círculos más próximos al autor como en otros, a través de copias ad familiares. Ha de suponerse que en ese momento Virgilio consideraba la obra, al igual que $\mathrm{Bu}$ cólicas, como esencialmente terminada y apenas expuesta al iudicium ajeno: ofrecía un texto de ultima manus, muy similar al conservado (salvo quizá, por ejemplo, en lo referente al libro $\mathrm{IV}^{27}$ ) y destinado sobre todo a deleitar a sus lectores, como apuntaba Séneca en Epist. 86, 15, tras citar Georg.2.58 ([...] ut ait Vergilius noster, qui non quid verissime sed quid decentissime diceretur aspexit, nec agricolas docere uoluit sed legentes delectare), más que a instruirlos, pese a lo que sugería el propio Virgilio en el comienzo de Eneida eliminado por Vario: gratum opus agricolis (cf. asimismo Plin.Nat. hist.18.300: sunt qui accendant in aruo et stipulas, magno Vergilii praeconio). No es verosímil que la obra yaciera entre el 29 y el 26 a. C. en los scrinia del autor o en los estantes de la apenas pública Biblioteca Palatina.

\section{La 'segunda edición' de Georg.4}

No se conserva ningún testimonio textual que acredite la noticia que Servio proporciona a propósito de la cuarta Geórgica (y que, según Setaioli, reafirmarían los Scholia Bernensia ad IV 468, ed. Hagen: propter Gallum 'Luciscum' poetam, qui nouis [sc. rebus] studere uolens ab Augusto occisus est ${ }^{28}$ ), según la cual ésta habría sido rehecha por Virgilio en su segunda mitad (a medio usque ad finem), de tal modo que el mito de Aristeo / Orfeo sustituyó 'en bloque' unas laudes Galli previas, como consecuencia de la caída en desgracia del poeta Cornelio Galo — praefectus en Egipto- - ante el ya nombrado 'Augusto' y de su consiguiente suicidio en el año 26, supuesto terminus post quem para la modificación. La intervención se habría producido a instancias de Augusto - según indica Servio (iubente Augusto), frente a fuentes de carácter más oficial (Svet.Div.Aug.66) — o bien por iniciativa del propio autor, según apuntaba Jacobson $(1984,314)$ y ha defendido Gagliardi $(2003,93)$ como «più logico y più degno dell'animo di Virgilio». Así, Galo habría sido tan amigo de Virgilio ut quartus georgicorum, a medio usque ad finem eius laudes teneret: quas postea iubente Augusto in Aristaei fabulam commutauit (Servio ad Buc.10.1); y, según se insiste a próposito de Georg.4.1, con diferencias de matiz respecto al anterior testimonio, sane sciendum, ut supra diximus, ultimam partem huius libri esse mutatam:

26 Como sugirió Diehl y aún consideraba posible Martin $(1985,664)$; al posible carácter irónico del segundo pasaje se referió acertadamente Thomas (1988, I 164).

27 Boldrer (1992, 193, n. 45), con referencia al ursae more de VD, líns. 81-84; Erren (2003, 4: «Es besteht m. E. kein zwingender Grund zu der Annahme, dass der edierte Text von dem damals vorgetragenen [29 a. C.] abweicht»). Al carácter concluso de Buc. y Georg. aludía Favorino en Gel.17.10. 5: Nam quae reliquit perfecta expolitaque quibusque inposuit census atque dilectus sui supremam manum, omni poeticae uenustatis laude florent $[\ldots]$.

28 Una última síntesis del argumento en Setaioli (2014, 177-178); Setaioli defiende la prioridad cronológica de la primera mitad de Georg.4 respecto a Eneida, relación que se invertiría en la segunda mitad del libro. 
nam laudes Galli habuit locus ille, qui nunc Orphei continet fabulam, quae inserta est, postquam irato Augusto Gallus occisus est.

Algunos estudiosos - en la estela de los trabajos de Jocelyn, Jacobson o últimamente Setaioli (2014, con réplica a Niehl 200729) — defienden todavía la presencia de esas laudes Galli en una primera edición de la obra, refiriéndose a la coherencia literaria e ideológica que representaría la supuesta inserción ${ }^{30}$ y a la atención que en principio debe prestarse al reiterado testimonio de Servio (concordante, por lo demás, con la autonomía literaria que ya en la Antigüedad se daba a la Aristaei / Orphei fabula: Goodfellow 2015, 68, 72). Para intentar resolver la cuestión se han aducido argumentos que afectan a la transmisión de la obra, insistiéndose en cómo la ausencia de cualquier vestigio de la hipotética versión primera parece desautorizar el relato serviano ${ }^{31}$ o por el contrario, desde una perspectiva más favorable a éste, en el problema que plantea la transmisión de los versos 290-293, referidos a la geografía de Egipto, pasaje que, a causa de la discrepancia en el orden de versos que ofrecen los tres manuscritos principales (M, P y R), algunos estudiosos han considerado como de sutura. La cuestión debe considerarse abierta. Suelen prevalecer los argumentos que desautorizan la nota de Servio, cuyo origen es desconocido pero para la que se han ofrecido explicaciones atendibles, como que sea resultado de una errónea interpretación erudita de la 'presencia' de Galo al final de Buc.10 (Conte 2013,97) o de las propias Geórgicas (en el exemplum mitológico que las concluye, redactado en un estilo literario afín al que se atribuye al malogrado poeta: Coleman 1962, 296; otras hipótesis en Erren 2003, 905-910). Aun así, no cabe excluir absolutamente la posible existencia de una versión inicial más o menos diferente de la que conocemos, quizá con un breve elogio de Galo perpaucis ex dictis (Conte 2013, 96, tras Nisbet), como en el caso de Mecenas o del propio Augusto ${ }^{32}$, si bien creemos que esta posibilidad sigue sin explicar los términos en que se expresa Servio respecto a la extensión del pasaje reelaborado (Hollis 2007: 229), que sugieren una translatio de cierta entidad (similar más bien a la practicada en Buc.10: cf. Serv.Ad 10.46).

Aun cuando se ha aludido a esa segunda edición como un mero 'fantasma' (Conte 2016a, 19 y 23), nada permite saber con certeza si ésta existió o no, de modo que

29 Para quien las laudes Galli sólo serían «verstechnische Anspielungen auf verlorene Dichtungen des Gallus» (150).

30 Así Gagliardi (2003, 61-114), quien apoya su hipótesis en la identificación latente entre Orfeo y Galo (Buc.6.6473, y 10), desestimada por Conte (2002, 63, n. 9; 95-96, n. 1).

31 Geymonat (2001, 294: «The first 'publication' of $G$. was of course oral, by means of the reading at Atella [...], and their rapid diffusion is [...] one of the factors which makes it quite impossible to lend credence to the silly tale in Servius about a revised edition of $G .4[\ldots] »)$; $c f$. , no obstante, Pecere (2015, XLI), así como, respecto a la ausencia de rastro de la primera edición de los Amores ovidianos, Tarrant $(1992,4)$.

32 En general, $c f$. Jacobson (1984), Mynors (1990, 296) y Thomas (1988, I 13-16); sobre la cuestión han vuelto Dorandi (2000, 146-147), partidario de suponer - tras Delvigo, últimamente en 2016 - la mutilación por parte de Virgilio de dos segmentos breves (en el entorno de 4.287-294 y 4.558-559), Conte (2002, 67), La Penna (2005, 94-95), Geymonat (2010, 353-354; escéptico al respecto), Gagliardi (2014, 71-72), Pecere (2015, XL-XLI), con alusión asimismo a los «pochi versi» que al inicio y al final del epilio elogiarían a Galo, o, últimamente, Conte (2016a, 24-25: «[...] the episode of Aristaeus and Orpheus goes back to the first draft of the Georgics [...] the epyllion featured in the text of Virgil long before Gallus fell into disgrace [...] presumably that eulogy consisted simply of a brief and passing allusion conveying affectionate respect; it is enough to recall how rare are the flattering words reserved by Virgil for his authoritative inspirer Maecenas, and how few lines are dedicated to the emperor himself. So it is impossible to believe that the words written in praise of Gallus occupied such a large portion of the text that they had to be replaced with the entire Aristaeus epyllion. In this respect, Servius's information is certainly false»). 
incluso quienes la niegan han recurrido a ella, más o menos directamente. Así quizá el propio Conte a propósito de 4.91-94 (cf. app. ad loc., Conte 2016a, 15-17) o de 4.291, al imaginar una edición antigua tan lábil — provista de ese verso 'flotante' y que entiende debería eliminarse para que el pasaje fluya ${ }^{33}$ - que se ve obligado a postular el acceso por parte de los 'copistas' a los restos (al margen) de un esbozo o texto provisional (2016a, 24: «The fact that the three best manuscripts have it out of place [...] suggests that it is a remnant from some previous draft of the poem, a remnant that survived in the margin of an ancient edition of Virgil and was subsequently inserted by copyists at different points in the text»). En realidad, la hipótesis sugiere la existencia de un arquetipo, cuestión ante la que Conte no parece decantarse (pese a la opinión de Butterfield 2011,398), pero que también se ha empleado para explicar el caso de Aen.2.567-588 (episodio de Helena, ausente en la tradición directa esencial pero probablemente auténtico y que debe remitirse, en principio, al modelo empleado por Vario y, quizá, por Tuca sub lege ea, ut nihil adderent: JERÓN. Chron., p. 166 Helm; cf. Pecere, 2015, XL-XLI) o el de Aen.4.1-2 (SERV.Ad init., ed. Jeunet-Mancy: Sane sciendum, licet primos duos uersus Probus et alii in quinti reliquerunt fine prudenter ad initium sexti esse translatos; nam [...]). Son cuestiones que deben debatirse (como ha sostenido, por ejemplo, Martín Puente 2015, 320) y no silenciarse (Heyworth 2014, a propósito de las laudes Galli: «[...] treating the story so is hardly the way to reduce its prominence in scholarly debate»), aun cuando el problema afecta sólo a la génesis del libro en cuestión y su solución no determina nuestro conocimiento de la obra conservada, que respondería en principio a la voluntad última de su autor.

La cuestión guarda estrecha relación con la que concierne a las supuestas 'variantes de autor' (Timpanaro 2001, 145-154), en unos casos descartadas por el propio Virgilio (1.6, lumina / numina: cf. Timpanaro 1986, 187, n. 12, 2001, 147-14834) mientras que en otros subsisten las dudas y sigue siendo constante la vacilación de los editores, como en 1.208, die / dies (Gel.9.14.7), o en 4.141, tinus / pinus (DS: ipsius manu duplex fuit scriptura ${ }^{35}$; cf. 4.112: tinosque / pinosque, así como Culex 407, Ov.Met.10. 98 y 103, etc.).

\section{Otras posibles intervenciones tempranas}

No es fácil determinar si el elogio de Augusto que aparece en Georg.1.24-42 y que concluye el proemio se compuso poco antes de la divulgación del poema, como ha

33 Cf. Coleman (1962, 300, n. 43), Mynors (1990, 298), Conte (2002, 67-68 y n. 6; 2016a, 23-25); solución distinta a la de Conte (2013) ha propuesto ya Holzberg (2016), tras Heyworth (2014); Geymonat (1984b, 832) señaló el pasaje, junto con la haplografía de me en Georg.4.148 (a propósito de Colum.10.5, cf. Velaza 2001, 28-29), como posible error presente ya en el arquetipo; el argumento de Horsfall al respecto (2000, XXIX: «it is not easy to see how the variation between the capital mss. could have occurred if they derive from an archetype but little older than them») no nos parece consistente.

34 Cf. Aen.3.600 (Delvigo 1990, 227-228), así como Horsfall 2000, 292-293, a Aen.7.430; cabe comparar Conte (1993, 210), a propósito de Aen.10.486 (uulnere / corpore / pectore), o Hardie (1994, 110 y 117), a propósito de Aen.9.189, soluti, y 236, sepulti.

35 Cf. Timpanaro (1986, 185-186); Harrison prefería tinus (2004, 116-117, 121, n. 44), como ha hecho Conte, pero $c f$. Parroni $(1974,349)$, Thomas (1988, II 166, 174), Erren (2003, 822-823), atendiendo más a la cuestión botánica. 
propuesto Thomas (1988, I 73: «a curious piece, presumably composed shortly before publication»), si bien parece lógico suponer que ya se había insertado en él cuando éste fue objeto de una primera recitación.

Más difícil resulta saber si debería remitirse a un momento anterior a la recitación en Atela otra supuesta modificación textual por parte de Virgilio, como es la que refiere GeL.6.20, 1-3 - sobre la base de lo hallado in quodam commentario- a propósito de Georg.2.224-225; se trata de la sustitución del topónimo Nola por el más 'eufónico' ora, como consecuencia de los resultados de un litigio entre Virgilio y los habitantes de la localidad citada, agraviados de ese modo por el autor del poema. La intervención, que el propio Gelio parece poner en duda al estilo de Livio (Ea res uerane an falsa sit, non laboro) y de la que también se hizo eco DS (ad 224), resulta de escasa verosimilitud ${ }^{36}$, aunque todavía se le concede cierta significación (Thibodeau 2011, 247). Como en los casos antes aludidos, tampoco afecta a la constitución del texto último.

Al menos un testimonio nos informa, asimismo, sobre la posible participación del público en esa etapa de transmisión oral de la obra, como es el recogido en $V D$, líns. 183-184, a propósito de Georg.1.299. Más que el rasgo de humor inherente, importa quizá el hecho de que alude a una recitación del propio Virgilio, distinta — cabe suponer- de la realizada en honor de Octaviano, antes o después, con carácter casi privado: alius recitante eo ex Georgicis: 'nudus ara, sere nudus' subiecit: 'habebis frigore febrem ${ }^{37}$. La anécdota - una mera «schoolboy story» a juicio de Mynors $(1990,69)$ - también fue recogida por Servio.

A estas primeras fases de difusión —oral y, a buen seguro, también escrita en cierta medida - cabe asignar ya probablemente parte de las variantes que nutrirían después una rica tradición indirecta, motivada sobre todo por esa rara mezcla de «semi-scholarly ingenuity and excitement» que el arte virgiliano suscitaba tanto entre sus admiradores como entre sus vehementes obtrectatores (Horsfall 2000, XXIX). Sólo cabe especular acerca de los ejemplares que pudieron servir de base para tan intensa actividad crítica. Es inverosímil que esa labor se llevara a cabo sobre la base de autógrafos virgilianos distintos de los quizá depositados en la Biblioteca Palatina, por mucho que pudieran haber circulado por Roma documentos auténticos de la mano del poeta (McDonnell 1996, 473; cf. Quint.1.7.20, Plin.Nat. hist.13.83) y pese a lo que sugieren pasajes como Gel.9.14.7 (a propósito de Georg.1.208: [...] facile his credam, qui scripserunt idiographum librum Vergilii se inspexisse, in quo [...]) y 13.21.1 (acerca de Georg.1.25: [...] in primo georgicon, quem ego inquit librum manu ipsius correctum legi [...]), así como, quizá, DS a Georg.1.12 (in Corn<elianis> 'equm', in authentico 'aquam', ipsius manu 'equm ${ }^{38}$ ), 66 (ipsius manu adiectum 'maturis solibus') o 69-70 (ipsius manu adiecti sunt [...]; cf. Timpanaro 2001, 147).

36 Cf. Holford-Strevens (1979), quien comparaba el comentario serviano a Aen.7.740 (como hará Mynors 1990, 130), Thomas (1988, I 198), con argumentos formales en contra, Geymonat (2001, 294, n. 4: «an indication of how and why people played, in the days before crossword puzzles, with the text of Virgil»), Horsfall (2001, 7, n. 48: «a late embroidery»), Holford-Strevens (2003, 189: «a silly tale»), Stok (2010, 118).

37 Sobre la posible intencionalidad del ignotus obtrectator (con eco, por ejemplo, en Isidoro, Etym. 2.21, 22: et habebis frigore messes), más allá del puro chiste, cf. Barchiesi (2004).

38 Cf. Thomas (1988, I 71), Timpanaro (1986, 186, n. 11; 2001, 148-149). A propósito de Aen.2, cf. Gel.2.3.5-6 («surely a fake», según Geymonat 2001, 295, n. 6) y, en general, Gamberale (1977) y Horsfall (2000, XXVIII), quien $(2006,114)$ desestimaba la posibilidad de que Probo se basase en autógrafos virgilianos o siquiera considerados como tales ( $c f$. Timpanaro 1986, 120-121, n. 73; 2001, 102). 
Tampoco es fácil determinar si la mencionada proliferación de variantes fue fruto, como consideramos más verosímil, de la consulta de manuscritos hoy perdidos (Munk 2009, 111) - a veces leídos con impericia por sus usuarios, como denunciaba Quint.9.4.39 - o más bien de conjeturas e «improvements» de los gramáticos antiguos, de meras listas de sinónimos confeccionadas para uso escolar (fenómeno patente, a nuestro juicio, en la tradición del 'retórico' Ovidio, mucho menos denso o inalterable en lo poético) o de simples fallos de memoria en el transcurso de una transmisión tan abigarrada. Es discusión que ha producido una amplia y polémica bibliografía, ya que suele sustentarse sobre hipótesis más o menos fundadas (Gamberale 2010) pero casi siempre indemostrables y a veces de puro carácter moral, al plantearse tan sólo la 'probidad' —o ausencia de tal—y la competencia —o ausencia de tal - de los gramáticos y eruditos implicados (y así desde antiguo; es significativo el testimonio de Gel.1.21.2: Hyginus autem, non hercle ignobilis grammaticus, o 7.6.5: Sed Hyginus nimis hercle ineptus fuit, cum [...]; cf. Boldrer 1992, 185, n. 13). Son vicisitudes del texto que carecen a menudo de una gran relevancia textual, que no siempre aparecen consignadas en los aparatos críticos y que, en cualquier caso, no empañan la extraordinaria calidad de conjunto de la parádosis virgiliana, fruto de una posada tradición directa, más que del perturbador caudal 'docto' o 'semidocto' que corría en paralelo (Geymonat 1977, 113; para la opinión contraria, que consideramos infundada, $c f$. Tarrant $(2012,47)$, en relación a Eneida: «[...] the notion that in a poem of early 10,000 verses the original reading has been faithfully preserved somewhere in the tradition in all but about 40 places strains belief»).

\section{Diversidad de criterios editoriales}

Las Geórgicas no ofrecen lugares afectados por tradición indirecta del tipo de Buc.4.62, célebre pasaje recientemente revisado, de nuevo, por Ottaviano (2016). Los problemas más frecuentes son meramente ortográficos, pero también requieren la aplicación de un criterio coherente por parte del editor. Respecto a la grafía de los acusativos plurales de los temas en -i, con su vacilación -is (-eis) / -es (Geymonat 1984a, Scappaticcio 2009a), la normalización practicada por Mynors (-is arcaizante, con escasas excepciones) resulta muy discutible, si se acepta que Virgilio mantenía el doblete en función de la sonoridad (así, frente al urbes de Aen.3.106, el urbisne de Georg.1.25, con Probo: Gel.13.21.4-5 ${ }^{39}$ ) o bien, desde la presunción contraria, que su ortografía era arbitraria e inconsistente (Butterfield 2011, 398 y n. ${ }^{40}$ ). Si no se opta por normalizar, la elección debería quizá contar con la opinión de Gaebel, quien, ampliando trabajos previos de Bömer, intentó aplicar de manera más o menos

39 Gaebel $(1982,106,127)$; en opinión de Conte $(2013,109)$, Vergilius enim, consilio auris suae usus, alterutram prout concursus uocalium postulabat praetulit terminationem; en cuanto al comportamiento de $\mathrm{M}$ y $\mathrm{P}$, cf. 110, n. 47.

40 A propósito de Aen.10.350-351 y de la alternancia tres / tris, de gusto helenístico, cf. Gel.13.21.10-11. Según Horsfall (2003, XVII), no hay motivo para suponer que Virgilio o sus copistas ofreciesen una norma, de modo que sigue «the usage of the majority of the best mss. even though this leads me into frequent inconsistency [...]» (cf. 2006, XLII-XLIII: «I am more interested in the ancient evidence for orthographic fluidity than in the need to produce a readable text in harmony with the orthographic conventions current among the best textual critics»). A propósito de las inconsistencias en el papiro de Galo (quom junto a maxima), cf. últimamente Scappaticcio (2009a, 115, n. 17). 
sistemática los criterios de eufonía y rima, clase de palabra, autoridad de las fuentes y manuscritos (incluso libro a libro; cf. 1982, 111, 115, donde considera debe prevalecer el comportamiento de MPayr y $t$ ). Puede asumirse, con Thomas, que cualquier propuesta ortográfica «is by and large familiar rather than necessarily 'correct'», en cuanto que responde a una convención editorial (1988, I 33) y que suele limitarse a reflejar lo más próximo a la norma clásica: equum en 1.13 y 2.542 , frente al equom de P que sólo Geymonat consigna y edita en ambos casos (pese a Horsfall 2003, 294, con referencia a Quint.1.7.26: «equus is the only acceptable orthography in an Augustan literary text»), inuertant en 1.65, frente al inuortant de M consignado y aceptado por Geymonat, o difficile est en 2.257, frente a la prodelisión difficilest de P tambien consignada y aceptada por Geymonat ${ }^{41}$. No obstante, el problema del «Virgil's own spelling» - cuyo planteamiento, en cuanto verdad inacessible, parece haber desaconsejado Ottaviano $(2013,24)$ y desahuciado Zetzel $(2016,562)$ - no debería tampoco eludirse, por insatisfactorio que siempre vaya a ser el resultado obtenido.

Los arcaísmos léxicos en las Geórgicas son más escasos proporcionalmente que en la Eneida y reflejan a menudo enianismos (Bettini 1984, 288). Puede destacarse el caso de Georg.1.208 (G. die / dies, editado por Geymonat; $c f$. Gel.9.14.742) o el del amaror que algunos editores han defendido para Georg.2.247 ( $c f$. Gel.1.21 $1^{43}$ ). Han sido menos llamativos los ejemplos de 2.344 (frigusque caloremque / calorque, a causa del hipérmetro y sobre la base de pasajes como Plaut.Merc.860: Conte 2013, 99-100, 2016a, 65), 425 (nutritor/nutritur: Bettini 1984, 288) o 4.437 (quoniam temporal — pro postquam, según apunta Servio - mantenido sin variantes en el conjunto de la tradición).

Frente al Orcus de los demás editores, Geymonat editó Horcus en 1.277, con P y quizá con Probo (Orchus, según $D S$ a Aen.3.357, por posible error en la transmisión ${ }^{44}$ ); su preferencia por el testimonio de $\mathrm{P}$ lo llevó asimismo a separarse de los editores precedentes, quizá sin acierto, en un caso como el de 3.77 (minantis, tam-

41 Geymonat edita uentumst en 3.98 (uentum est Conte), tantaest en 3.112 (tantae est Conte); cf., no obstante, Thomas (1988, I 32, n. 90), Mynors (1990, 111), a Georg.2.82 (miratastque Geymonat y Conte). Geymonat, por lo demás, restituye quom, maxumus y similares. En cuanto a neque / nec, Conte «normally prints neque rather than nec where the capital mss are divided, including Geo. 1.426, when R has neque against nec in M [y en Sen. Epist.88.16, añadiríamos]; but not at 3.216, where nec is for some reason preferred» (Heyworth 2014).

42 Timpanaro (1986, 120-121, n. 73, y 2001, 102), Thomas (1988, I 104), Holford-Strevens (2003, 190). La variante die tiene mayor apoyo en los manuscritos, es difficilior (aunque «not uncommun»: Mynors 1990, 48), y «the sound of dies somnique is less elegant» (Thomas 1988, I 104, con Bettini 1984, 288).

43 Boldrer (1992, 184, n. 4) propuso aceptar amaror, con editores previos (así Ribbeck o F. della Corte), pero con sensus como acusativo plural dependiente de temptantum. Tras las reservas de Jocelyn $(1988,201)$ o Thomas (1988, I 202), Mynors $(1990,132)$ aludió a la «infelicity» del sapor ... amaror y a la preferencia de los gramáticos por el arcaísmo; $c f$. asimismo Holford-Strevens (2000, 2003, 191, 211) y últimamente, con resignación, Conte (2016a, 62: «So now the authentic reading sensu torquebit amaro, while not inherently banal, could be claimed by some as being "incontestably" the lectio facilior, if one confronts it with the precious Lucrezian [sic] pearl sensus ... amaror»)).

44 Cf. Courtney (1981, 24-25: «no doubt that Orcus is what Virgil intended»), Zetzel (1984, 40-41), Timpanaro (2001, 47-48); Horcus habría sido una corrección —o conjetura - antigua, sobre la base de Hes.Op.804 (cabe comparar 1.17: si] seu Teócr.1.124, o 1.373, donde prudentibus, con Mh, sugiere Arato.Phaen.973

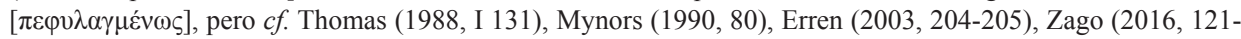
123); cf. 1.332, Atho, con Teócr.7.77, pese a la dificultad métrica y a su desautorización por parte de Courtney (1981, 26-27): Athon, con los códices y Valerio Flaco 1.664). Heyworth (2014) defiende para 3.19 el Molorci exclusivo de P, frente al Molorchi de los editores. 
bién con Sen.Epist.95.68, frente a minacis/minaces), así como, ya sin mediación de testimonio indirecto, en 3.426 (corpore frente a pectore) y 3.535 (arduos, difficilior en lo métrico a causa de la sinicesis y secundado por Conte frente a altos, posible persistencia en 3.412). Editó asimismo feruit en 4.169, lectura atribuida a Hebro en los Scholia Bernensia, frente al feruet de los demás editores (incluido Mynors, pese a sus reservas en 1990, 280: «perhaps we should write feruit»); en 2.332 eligió germina (Celsus ait germina reliquisse Vergilium, según DS), frente al gramina de los demás editores (defendido por Boldrer 1991). Fue distinto su criterio en lugares como 3.435 (nec, apenas explicado como error por Mynors (1990, 245), frente al ne también presente en Quint.9.3.21).

Mynors aceptó dicere en 2.106 (con MV, Columela o Amiano Marcelino), frente al discere de los demás editores, en un pasaje descabalado en los aparatos y que apenas ha suscitado comentario crítico (un simple paralelo ofrece Erren 2003, 341). En 2.52 Thomas admite el uoces de Servio, seguramente en decisión acertada y secundada por Conte, frente al uoles de $\mathrm{M} \gamma^{1}$ (Mynors 1990, 107; Thomas 1988, I 166) y en 2.71 (1988, I 169) admite el fagus de Prisciano y dos manuscritos carolingios, también en esto secundado por Conte (tras Timpanaro 2001, 141-142 y n. 209, Conte 2016a, 4-5).

Por lo demás, nuestro texto carece de lagunas e interpolaciones evidentes (en general Polara 1985): de versos repetidos ${ }^{45} \mathrm{o}$ susceptibles de atétesis (con la excepción de 4.338 = Aen. 5.826 y, quizá, de $2.433^{46}$ o de 4.291: Conte, Heyworth 2014), así como de trasposiciones de importancia o, al menos, incontrovertibles ${ }^{47}$.

\section{Conclusiones}

1. Las noticias relacionadas con la difusión inicial de Geórgicas son de carácter anecdótico y quizá ficticias - total o parcialmente - en su mayoría, si bien no es fácil aducir motivos objetivos que demuestren su invención por parte de gramáticos o eruditos; esas supuestas «fantasies sometimes found in commentaries» (Heyworth 2014, acerca de Georg. 1.6 y 13) no son relevantes para la constitución de nuestro texto, que debería procurar reflejar la voluntad última del poeta y no posibles estadios anteriores de su composición (Conte 2013, 100-101); no obstante, dan cuenta de los mecanismos que hicieron surgir ciertas variantes antiguas y deben figurar en los aparatos críticos, dirigidos a justificar la fijación del texto pero también a informar al usuario de la edición sobre las vicisitudes de su transmisión y recepción.

2. La tradición indirecta no se restringe a esas anécdotas ni a las variantes documentadas en citas de autores como Quintiliano o Séneca, fruto a veces de ejemplares deficientes y de la adaptación de las respectivas transmisiones a la vulgata virgiliana,

45 Pese a Georg.1.154 (cf. Buc.5.37), 1.304 (=Aen. 4.418; según DS, Probus sane sic adnotavit: Si hunc uersum omitteret, melius fecisset), 1.494 (cf. 2.513), 3.263 (cf. Aen.4.308); $c f$. Geymonat (1977, 115 y 123; 1986, 114115).

46 Ausente en M, en Servio y en los Schol. Bern.; Conte (2016a, 6-7) lo considera pregunta retórica incongruente con el contexto y que, frente a la práctica virgiliana, se añade a una segunda. Es distinto el caso de I 389a Geymonat, sólo añadido en $M$ (Pomponio Leto) y $\gamma^{1}$.

47 Tres casos esgrimió Courtney (1981, 16-17), y uno más en 2002-2003, 192 (4.521 tras 4.518); sobre 4.203-205 cf. Conte (2016a, 18-20), justificando su inserción tras el verso 196 (cf. 3.120-122 tras 3.96, con Bentley y Ribbeck). 
más que de la mala memoria (cf. Geymonat al stellasque de Georg. 1.424 en Sen. Epist.88.168) o del inverosímil uso de ediciones deleznables: muchas variantes de procedencia indirecta invadieron muy temprano la transmisión manuscrita — sobre todo la de ámbito escolar y erudito, rica en variaciones sinonímicas, inserción de paralelos y conjeturas diversas - y lograron mimetizarse en su seno hasta confundirse con las meras faltas de copia, de las que no difieren ya por su fisonomía, sino por la causa que, en última instancia, las originó. El ejemplo más evidente de esta confluencia lo ofrece, sin duda, el nutrido corpus de escolios virgilianos.

3. Son muy pocos los ejemplos en los que la tradición indirecta resulta determinante, pero siempre son casos de interés - al menos propedéutico — para la crítica textual virgiliana en su conjunto; tales variantes han solido recibir el apoyo de un editor u otro, dispuesto a buscar 'trigo entre la parva' (Conte 2013, 99, n. 12), e incluso un favor unánime o casi unánime (así en 3.230, pernox / pernix, con recientes observaciones de Conte 2016a, 61-68). Fue grande el respeto hacia la tradición indirecta por parte de editores como Ribbeck o Sabbadini, arrastrados por su propia concepción de la historia del texto; entre los modernos ha destacado Timpanaro y, en la práctica, tanto Geymonat (quien combinó su aprecio hacia la tradición indirecta con su preferencia por la transmisión frente a conjeturas innecesarias) como, siempre intentando justificar en el aparato sus decisiones, Conte ${ }^{49}$.

4. La mayor o menor atención a la tradición indirecta es reflejo de una manera de concebir la transmisión antigua y sus factores; no debería responder al grado de 'credulidad' —o elegante 'incredulidad'- del editor, ni es incompatible, per se, con el respeto a la tradición directa o la estemática (asociación que ha establecido Zetzel (2014): «Timpanaro believed strongly in the value of indirect tradition; often useful indeed, but in Timpanaro's later work it turns into a rejection of direct tradition and thus of stemmatics»); de hecho, es una manera lícita de aplicar el criterio de antiquior potior y, a menudo, el de difficilior potior, por dudoso que éste resulte en ocasiones (Conte 2016a). Así, se ha consolidado limo en Aen.12.120, con Higino, Capro y la Lex Irnitana, y sigue encontrando reconocimiento el difícil floros de Probo y Servio en 12.605 (Conte, Harrison 2014, 160), aunque Tarrant (2012) haya vuelto a optar por flauos. El 'infeliz' amaror de Higino y Servio (Georg.2.247), en cambio, sigue esperando su reivindicación más moderna. Pese al auxilio que presta la Filología en su aparente progreso cotidiano, mucho es lo que dirime al final el 'gusto' del editor (Parroni 1974, 346), particularmente en los casos de tradición indirecta. Al defender sus decisiones, editores y estudiosos suelen apelar a la célebre conjunción de et ratio et res ipsa (Bentley ap. Tarrant 1992, 3, Kraggerud 2016), por mucho que esa ratio no sea tan fácil de aislar o tan universal como se presume, quedando a menudo diluida en mera sententia, es decir, en desatención hacia la rerum ueritas y en injustificado aprecio hacia la propia, ipsissima ratio. Es fácil detectar inconsistencias en el proceder editorial: hay problemas que apenas admiten una reducción plenamente fundada (como los ortográficos) y para la selección de variantes no cabe la aplicación rígida de criterios. No obstante, consideramos preferible una edición

48 El caso de Aen.6.95-96 (quam/qua), citado por Sen.Epist.82.18-19 y con sendas variantes en su tradición manuscrita, no nos parece tan 'incuestionable' como sostiene Velaza $(2010,218)$ al defender quam.

49 Para el caso de Eneida $c f$. Butterfield $(2011,399)$ : «in numerous places wisely prefers [sc. Conte] against the direct tradition the text preserved by Servius et al., e.g. 5.720 (animum), 6.383 (terra) and 12.120 (limo); in two other cases - quosne at 10.673 and floros at 12.605 - neither seems fully persuasive against the ancient paradoses». 
que, al menos, se proponga seguirlos que otra que, alegando 'eclecticismo', renuncie a estudiar la historia del texto (bajo el común pretexto de lectiones ponderandae... non codices) y a intentar acercarse en la medida de lo posible, con los muchos medios hoy disponibles, al original del autor, ese inquietante horizonte $\mathrm{y}$, para algunos grandes filólogos, casi tabú.

\section{Referencias bibliográficas}

Ammannati, G. (2007), «Ancora sulla sottoscrizione del console Asterio e sulla datazione del Virgilio Mediceo», MD 58, 227-239.

—, (2009), «Prime precisazioni sui primi correttori del Virgilio Palatino», MD 62, 253-258.

Ammannati, G.; A. Pittà (2013), «L'indipendenza dei codici P e $\gamma$ di Virgilio nelle Georgiche», $M D$ 70, 63-76.

Barchiesi, A. (2004), «Quando Virgilio era un moderno: una delle più antiche recite delle Georgiche, e il contesto di una spiritosaggine», MD 52, 21-28.

Baschera, C., «Servius Danielinus and Scholia Veronensia: clues to their relationship», en Casali - Stok 2008, 207-215.

Bettini, M. (1984), «arcaismi», en EV I, 287-291.

Boldrer, F. (1991), «Virgilio, Georg. 2, 332», MD 27, 145-157.

-, (1992), «Quod Iulius Hyginus affirmatissime contendit (Gell. 1, 21 ad Verg. Georg. 2, 247)», MD 29, 183-198.

Bonaria, M. (1971), «Appunti per la storia della tradizione virgiliana nel IV secolo», en Bardon H.- Verdière R. (eds.), Vergiliana. Recherches sur Virgile, Leiden, Brill, 35-40.

Brugnoli, G. (1988), «Servio», en EV IV, 805-813.

Brunhölzl, F. (1971), «Zu den sogenannten codices archetypi der römischen Literatur», en Autenrieth J.- Brunhölzl F. (eds.), Festschrift Bernhard Bischoff zu seinem 65. Geburts$\operatorname{tag}[\ldots]$, Stuttgart, Hiersemann, 16-31.

Butterfield, D. (2011), res. de Conte 2009, en ExClass 15, 397-401.

Cadili, L. (2003), «Gli Scholia Bernensia alle Georgiche di Virgilio», Lexis 21, 381-392.

-, (2008), «Scholia and authorial identity: the Scholia Bernensia on Vergil's Georgics as Servius auctus», en Casali - Stok 2008, 194-206.

Casali, S. - F. Stok (eds.) (2008), Servio: stratificazioni esegetiche e modelli culturali Servius: exegetical stratifications and cultural models, Bruselas, Latomus.

Cavallo, G. (2008), La scrittura greca e latina dei papiri. Una introduzione, Pisa - Roma, Fabrizio Serra.

Coleman, R. (1962), «Gallus, the Bucolics, and the ending of the fourth Georgic», AJPh 83, 55-71 [= Hardie 1999, 289-300].

Conte, G. B. (1993), res. de S. J. Harrison, Virgil, Aeneid 10, Oxford, Clarendon Press, 1991, en JRS 83, 208-213.

-, (2002), Virgilio: l'epica del sentimento, Turín, Einaudi.

—, (2009), P. Vergilius Maro. Aeneis. Recensuit atque apparatu critico instruxit..., Berlín Nueva York, De Gruyter.

-, (2013): cf. Ottaviano - Conte 2013.

-, (2016a), Critical notes on Virgil: editing the Teubner text of the Georgics and the Aeneis, Berlín - Boston, De Gruyter.

—, (2016b), Ope ingenii: experiences of textual criticism, Berlín et al., De Gruyter. 
Courtney, E. (1981), «The formation of the text of Vergil», BICS 28, 13-29.

—, (2002-2003), «The formation of the text of Vergil - again», BICS 46, 189-194.

Cova, P. V. (1990), «Vario Rufo, Lucio», en EV V 1, 441-443.

Cugusi, P. (2008), «Citazioni virgiliane in iscrizioni e graffiti (e papiri)», BSL 38, 478-534.

Daintree, D. - M. Geymonat (1988), «Scholia non Serviana», en EV IV, 706-720.

della Corte, F. (1991), «Virgilio», en EV V 2, 2-97.

Delvigo, M. L. (1987), Testo virgiliano e tradizione indiretta. Le varianti probiane, Pisa, Giardini.

-, (1990), «Clarissima mundi lumina: il proemio delle Georgiche e una presunta variante d'autore», SIFC 83, 215-228.

-, (2016), «Preistoria e protostoria del testo virgiliano: ancora sul preproemio dell'Eneide e le laudes Galli», en J. Velaza (ed.), From the protohistory to the history of the text, Frankfurt am Main, Peter Lang, 207-222.

Dorandi, T. (1991), «Den Autoren über die Schulter geschaut. Arbeitsweise und Autographie bei den antiken Schriftstellern», ZPE 87, 11-33.

-, (2000), Le stylet et la tablette. Dans le secret des auteurs antiques, París, Les Belles Lettres.

Erren, M. (1985), P. Vergilius Maro. Georgica. Band I: Einleitung, Praefatio, Text und Übersetzung, Heidelberg, Winter.

—, (2003), P. Vergilius Maro. Georgica. Band II: Kommentar, Heidelberg, Winter.

Escobar, Á. (2008), «La tradición antigua del texto virgiliano: notas acerca de algunas hipótesis recientes», ExClass 12, 25-47.

$E V=$ F. della Corte, Enciclopedia Virgiliana, Roma, I, A-DA (1984) - II, DE-IN (1985) - III, IO-PA (1987) - IV, P-S (1988), V,1, T-Z (1990), V,2 (1991).

Gaebel, R. E. (1982), «The varied use of -es and -is for the accusative plural of $i$-stem words in Vergil's Georgics», Latomus 41, 104-131.

-, (1985), «Roman cursive influence in the text of the Georgics», RhM 128, 305-313.

Gagliardi, P. (2003), Gravis cantantibus umbra. Studi su Virgilio e Cornelio Gallo, Bolonia, Pàtron.

—, (2009), «Per la datazione dei versi di Gallo da Qașr Ibrîm», ZPE 171, 45-63.

-, (2014), Commento alla decima ecloga di Virgilio, Hildesheim, Olms.

Galinsky, K. (2002), res. de Zwierlein 1999 en Gnomon 74, 685-687.

Gamberale, L. (1977), «Autografi virgiliani e movimento arcaizzante», en Atti del Convegno virgiliano sul bimillenario delle Georgiche. Napoli 17-19 dicembre 1975, Nápoles, 359-367.

-, L. (2010), «A proposito di filologia virgiliana», en <http://www.accademiafiorentina.it/ RelTimp/filologia_virgiliana.pdf> [30.11.16].

Geymonat, M. (1984a), «accusativi plurali», en $E V \mathrm{I}, 13-14$.

—, (1984b), «codici», en EV I, 831-838.

-, (1985a), «Eneide: La problematica ecdotica del testo», en EV II, 286-296.

—, (1985b), «Filargirio», en EV II, 520-521.

-, (1985c), «interpunzione», en $E V$ II, 998-1000.

—, (1986), «Interventi sui più antichi codici virgiliani: memoria di singoli manoscritti perduti o sintesi di precedenti edizioni critiche del testo?», en Gigante 1986a, 107-124.

-, (2001), «The transmission of Virgil's works in Antiquity and the Middle Ages», en Horsfall 2001, 293-312 [trad. Horsfall].

—, (2008), P. Vergili Maronis opera edita anno MCMLXXIII iterum recensuit..., Roma, Edizioni di Storia e Letteratura [ $1^{\text {a }}$ ed. 1973].

—, (2010), res. de Rivero García et al., en ExClass 14, 353-356. 
Giardina, G. (2009), «Nuovi emendamenti al testo delle Georgiche di Virgilio», QUCC 121 (n. s. 92), 157-166.

Gigante, M. (ed.) (1986a), La fortuna di Virgilio. Atti del Convegno internazionale (Napoli 24-26 ottobre 1983), Nápoles, Giannini.

—, (1986b), «Virgilio da Pompei all’Egitto», en Gigante 1986a, 7-43.

Goodfellow, M. S. (2015), «Early reception of Vergil's Georgics: protinus Italiam concepit», Vergilius 61, 43-76.

Hardie, P. (1994), Virgil. Aeneid, Book IX, Cambridge, University Press [reimpr. 2000].

-, (ed.) (1999), Virgil. Critical assessments of classical authors, II: Georgics, Londres Nueva York, Routledge.

Harrison, S. (2004), «Virgil's Corycius senex and Nicander's Georgica: Georgics 4.11648», en Gale M. (ed.), Latin epic and didactic poetry. Genre, tradition and individuality, Swansea, The Classical Press of Wales, 109-123.

-, (2014), res. de Tarrant 2012, en Mnemosyne 67, 159-161.

Heyworth, S. J. (2014), res. de Ottaviano - Conte 2013, en <http://bmcr.brynmawr. edu/2014/2014-02-47.html> [30.11.16].

Holford-Strevens, L. A. (1979), «Nola, Vergil and Paulinus», CQ 29, 391-393.

-, (2000), «'And by the bitter taste disclose the ground' (Gell. I 21 on Verg. Georg. II 246 f.)», Eikasmos 11, 309-34.

Holford-Strevens, L. A. (2003), Aulus Gellius. An Antonine scholar and his achievement, revised ed., Oxford, University Press [1 $1^{\mathrm{a}}$ ed. 1988].

Hollis, A. S. (2007), Fragments of Roman poetry (c. 60 BC-AD 20). Edited with introduction, translation and commentary by..., Oxford, University Press.

Holtz, L. (2011), «Servius et Donat», en Bouquet M. - Méniel B. (colab. Ramires G.), Servius et sa réception de l'Antiquité à la Renaissance. Études réunies par..., Rennes, Presses Universitaires, 205-217.

Holzberg, N. (2016), Publius Vergilius Maro. Hirtengedichte, Bucolica - Landwirtschaft, Georgica, Berlín - Boston, De Gruyter.

Horsfall, N. (2000), Virgil, Aeneid 7. A commentary by..., Leiden - Boston - Colonia, Brill.

-, (ed.) (2001), A companion to the study of Virgil. Second revised edition, Leiden - Boston - Colonia, Brill [1 $1^{\mathrm{a}}$ ed., 1995].

—, (2003), Virgil, Aeneid 11. A commentary by..., Leiden - Boston, Brill.

—, (2006), Virgil, Aeneid 3. A commentary by..., Leiden - Boston, Brill.

Jacobson, H. (1982), «Vergil, Georgics 3, 280-281», MH 39, 217.

—, (1984), «Aristaeus, Orpheus and the Laudes Galli», AJPh 105, 271-300 [= Hardie 1999, 301-327].

Jeunet-Mancy, E. (2012), Servius. Commentaire sur l'Énéide de Virgile, livre VI. Texte établi, traduit et commenté par..., París, Les Belles Lettres.

Jocelyn, H. D. (1985), «The annotations of M. Valerius Probus, III: some Virgilian scholia», CQ 35, 466-474.

—, (1988), res. de Timpanaro 1986, en Gnomon 60, 199-202.

Kallendorf, C. (2015), The Protean Virgil: material form and the reception of the classics, Oxford, University Press.

Kaster, R. A. (1995), C. Suetonius Tranquillus. De grammaticis et rhetoribus. Edited with a translation, introduction and commentary by..., Oxford, University Press [reimpr. 2003].

Katz, J. T. (2008), «Vergil translates Aratus: Phaenomena 1-2 and Georgics 1.1-2», MD 60, 105-123.

Kiss, D. (2012), «Zu den Fragmenten 5-6 Velaza des M. Valerius Probus», Hermes 140, 118-120. 
Kraggerud, E. (2011), res. de Conte 2009, en SO, 210-225.

-, (2016), Vergiliana: critical studies on the texts of Publius Vergilius Maro, Londres, Routledge.

La Penna, A. (2005), L'impossibile giustificazione della storia. Un 'interpretazione di Virgilio, Roma - Bari, Laterza.

Lehnus, L. (1988), «Probo», en EV IV, 284-286.

Marichal, R., «Quelques apports à la tradition ancienne du texte de Virgile», RÉL 35, 1957, 81-84.

Martin, R. (1985), «Georgiche», en EV II, 664-669.

Martín Puente, C. (2015), «Hor., Sat. I 10.1-8, Verg., Aen. II 567-588 y Ou., Am. III 5: el papel del autor como editor», Emerita 83, 309-331.

McDonnell, M. (1996), «Writing, copying and autograph manuscripts in ancient Rome», $C Q$ 46, 469-491.

Moretti, P. F. (2008), «Proba e la tradizione del testo di Virgilio. Qualche riflessione», Acme 61, 61-86.

Munk Olsen, B. (2009), L'étude des auteurs classiques latins aux XIe et XIIe siècles, IV-1re partie: La réception de la littérature classique. Travaux philologiques, París, CNRS.

Myers, K. S. (2009), Ovid. Metamorphoses, book XIV, Cambridge, University Press.

Mynors, R. A. B. (1972), P. Vergili Maronis opera recognovit brevique adnotatione critica instruxit..., reimpr. con correccs., Oxford, Clarendon Press [reimpr. 1985; $1^{\mathrm{a}}$ ed. 1969].

-, (1990), Virgil. Georgics. Edited with a commentary by... with a preface by R. G. M. Nisbet, Oxford, Clarendon Press.

Niehl, R., «Vergils angebliche Revision der Georgica», Hyperboreus 13, 137-150.

Nisbet, R. G. M. - N. Rudd (2004), A commentary on Horace, Odes, book III, Oxford, University Press.

Ottaviano, S. (2016), «A singular smile: note on Virgil, Eclogue 4. 62-63 with an appendix on syntax», Hermes 114, 497-511.

Ottaviano, S. - G. B. Conte (2013), P. Vergilius Maro. Bucolica. Edidit et apparatu critico instruxit S. Ottaviano - P. Vergilius Maro. Georgica. Edidit et apparatu critico instruxit G. B. Conte, Berlín - Boston, De Gruyter.

Parroni, P. (1974), res. de Geymonat 1973, en RFIC 102, 346-351.

Pecere, O. (2015), Roma antica e il testo: Scritture d'autore e composizione letteraria, Roma - Bari (ed. digital; $1^{\mathrm{a}}$ ed. 2010).

Perret, J. (1973), res. de Geymonat 1973 en RÉL 51, 1973, 379-381 [= RPh 48, 1974, 356-357].

Perutelli, A. (2005), «Gli studi sulle Georgiche (1984-2003)», en La Penna 2005, 109-112.

Petrucci, A. (1987), «papiri», en EV III, 964-965.

Polara, G. (1985), «interpolazioni», en EV II, 996-997.

Reynolds, L. D. (ed.) (1986), Texts and transmission. A survey of the Latin classics, repr. with corrections, Oxford, Clarendon Press [ $1^{\mathrm{a}}$ ed. 1983].

Rivero García, L. - Estévez Sola, J. A. - Librán Moreno, M. - Ramírez de Verger, A. (2009), P. Virgilio Marón. Eneida, I, libros I-III, Madrid, CSIC.

Salanitro, G. (2013), «Tradizione indiretta virgiliana e poesia centonaria», Sileno 39 [=W. Lapini (ed.), Omaggio a Sebastiano Timpanaro], 350-356.

Scappaticcio, M. C. (2009a), "'Ambiguità' grafiche e morfologiche: Virgilio, i papiri e gli accusativi in -es / -is», BSL 39, 2009, 112-122.

—, (2009b), «Virgilio e la 'filologia dei papiri': Aen. 1, 618 e il PColt 1», MD 62, 2009, 239-251.

-, (2013), Papyri Vergilianeae. L'apporto della papirologia a la storia della tradizione virgiliana (I-VI d. C.), Lieja, Presses Universitaires. 
Setaioli, A. (2014), «Ancora a proposito della doppia redazione del finale delle Georgiche», Prometheus 40, 175-179.

Somerville, T. (2007), «The orthography of the new Gallus and the spelling rules of Lucilius», ZPE 160, 59-64.

Stok, F. (2010), «The life of Vergil before Donatus», en Farrell, J. - Putnam, M. C. J. (eds.), A companion to Vergil's Aeneid and its tradition, Wiley-Blackwell, Malden - Oxford Chichester, 107-120.

-, (2012), «Il testo virgiliano di DS», Eruditio antiqua 4, 101-135.

Tarrant, R. J. (1992), «L'édition de la littérature latine classique», en Hamesse, J. (ed.), Les problèmes posés par l'édition critique des textes anciens et médiévaux, Lovaina la Nueva, $1-56$.

-, (2012), Virgil. Aeneid. Book XII, Nueva York, Cambridge University Press.

Thibodeau, P. (2011), Playing the farmer. Representations of rural life in Vergil's Georgics, Berkeley - Los Angeles - Londres, University of California Press.

Thomas, R. F. (1988), Virgil. Georgics. Volume 1 (books I-II) - Volume 2 (books III-IV), edited by..., Cambridge - Nueva York - Melbourne, Cambridge University Press [reimpr. 1998].

Timpanaro, S. (1986), Per la storia della filologia virgiliana antica, Roma, Salerno Editrice. -, (2001), Virginialisti antichi e tradizione indiretta, Florencia, Olschki.

Velaza, J. (1998), «Teste Quintiliano: Quintiliano como fuente de transmisión indirecta y la prehistoria del texto virgiliano», en T. Albadalejo et al. (eds.), Quintiliano: Historia y actualidad de la retórica. Actas del congreso internacional..., II, Calahorra, 1087-1098.

-, (2001), Itur in antiquam silvam. Un estudio sobre la tradición antigua del texto de Virgilio, Frankfurt am Main, Peter Lang.

—, (2010), «Verg. Aen. 6, 95-96 (y el oficio de editor)», en E. Borrell Vidal - L. Ferreres Pérez (eds.), Artes ad humanitatem, II, Barcelona, Secció Catalana de la SEEC.

Zago, A. (2016), «Vitia et virtutes orationis nel commento di Servio a Donato (GL IV, pp. 443, 28 - 448, 17): edizione critica, traduzione, note di commento», Latinitas, n. s. 4 , 93-136.

Zetzel, J. E. G. (1984 [1981]), Latin textual criticism in Antiquity, Ayer, Salem.

—, (2000), res. de Zwierlein 1999, en Vergilius 46, 181-191.

-, (2014), res. de S. Timpanaro - G. Ramires, Carteggio su Servio (1993-2000), Pisa, 2013, en <http://bmcr.brynmawr.edu/2014/2014-04-41.html> [30.11.16].

—, (2016), res. de Scappaticcio 2013, en Gnomon 88, 561-563.

Zwierlein, O. (1999), Die Ovid- und Vergil-Revision in tiberischer Zeit, I: Prolegomena, Berlín - Nueva York, de Gruyter. 